\title{
Bilateral papilledema in a child with osteogenesis imperfecta
}

\author{
Selam Yekta Sendul ${ }^{1 *}$, Cemile Ucgul Atilgan², Semra Tiryaki ${ }^{1}$ and Dilek Guven ${ }^{1}$
}

\begin{abstract}
Background: To present a female child patient with osteogenesis imperfecta who had bilateral papilledema. Case presentation: A twelve-year-old girl with osteogenesis imperfecta was referred to our clinic. Bilateral best corrected visual acuity of the patient was $5 / 10$ (corrected with +3.50 for right eye, +5.00 for left eye) with a standard Snellen scale at a distance of a $6 \mathrm{~m}$. Anterior chamber, iris and lens examination of both of her eyes were unremarkable. In her fundus examination, bilateral stage 2 papilledema and the wrinkles in papillomacular area were noticed. Optical coherence tomography images revealed the macular pucker and thickening in the retinal nerve fibre layers of both eyes. Computed tomography images revealed that there were ossifications in the optic chiasma and occlusion in all periorbital sinus areas.

Conclusion: Osteogenesis imperfecta is a rare, autosomal dominant connective tissue disorder characterised by bone fractures, deafness and blue sclera. We would like to draw attention to the clinical course of our patient with computed tomography, optical coherence tomography and visual field findings.
\end{abstract}

Keywords: Optical coherence tomography, Osteogenesis imperfecta, Papilledema, Visual field defect

\section{Background}

Osteogenesis imperfecta (OI) is a heritable disease of the connective tissue characterised by lower bone mass, bone fragility and skeletal deformities. The major health consequences in OI arise from functionally compromised bone. Short stature, blue sclera, laxity of ligaments, non-union of fractures, keloid and hyperplastic callus formation are additional but variable symptoms [1].

A typical ocular finding of OI is blue sclera [2]. Additional ocular findings are the decreased ocular rigidity [3], refractive errors (myopia, hyperopia, astigmatism), glaucoma, keratoconus, keratoglobus, corneal opacity, small corneal diameter, corneal thinning, cornea plana, congenital Bowman's layer agenesis, vitreous and retinal haemorrhage, choroidal neovascularization, retinal detachment, optic neuropathies and optic atrophy [4-12]. The study was conducted in accordance with the tenets of the Declaration of Helsinki by obtaining written consent from the parents as well as the patient.

\footnotetext{
* Correspondence: sysendul@hotmail.com

${ }^{1}$ Department of Ophthalmology, Sisli Hamidiye Etfal Training and Research Hospital, Etfal Street, 34280 Istanbul, Sisli, Turkey

Full list of author information is available at the end of the article
}

\section{Case presentation}

A twelve-year-old female patient with $\mathrm{OI}$ was referred to our clinic for routine eye examination from the genetic department. Bilateral best corrected visual acuity of the patient was obtained $-5 / 10$ (corrected with +3.50 for right eye, +5.00 for left eye) - with a standard Snellen scale at a distance of $6 \mathrm{~m}$. She had growth retardation and typical facial appearance compatible with OI, such as triangular shaped face, large skull, a prominent nose, elongated columella of the nose, smaller maxilla, slightly larger mandible (Fig. 1). Anterior chamber, iris and lens examination of both her eyes were unremarkable. Neither of her eyes had blue sclera. Both glob measurements measured by Hertel's exophthalmometer were $21 \mathrm{~mm}$. Bilateral corneal diameters were $10 \mathrm{~mm}$ at vertical axis and $9.5 \mathrm{~mm}$ at horizontal axis. Bilateral intraocular pressures were $12 \mathrm{mmHg}$ with Applanation tonometry. Examinations of motolities of both her eyes were normal. Central corneal thicknesses of her right and left eyes with ultrasound corneal pachymetry were 500 and 510 microns, respectively. In her fundus examination, bilateral stage 2 papilledema according to Frisen Scale and wrinkles in papillomacular bundle were noticed (Fig. 2a). Bilateral colour vision examinations by 


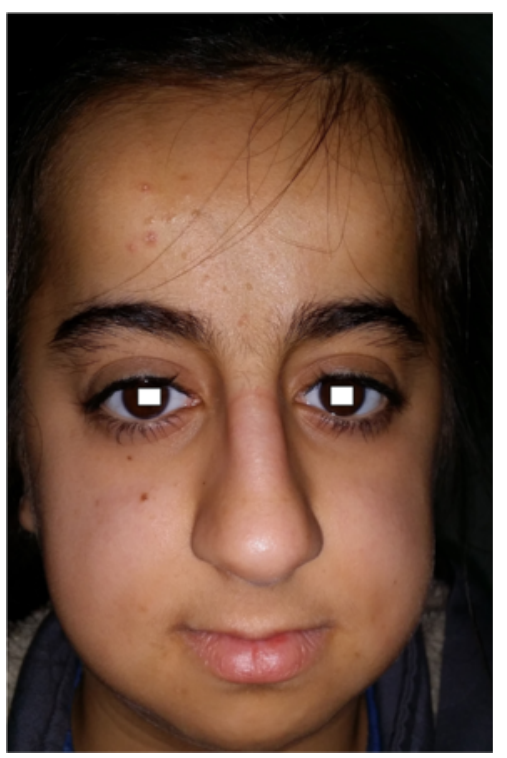

Fig. 1 Typical facial appearance of twelve-year-old female patient with osteogenesis imperfecta

Ishihara plates were normal. Initially, optical coherence tomography (OCT) images revealed the macular pucker and thickening in the retinal nerve fibre layer (RNFL) of both her eyes (Fig. 3a, b) but after 5 months when the papilledema subsided, the distinct thinning in both RNFL was obvious (Fig. 2b). Computed tomography (CT) images revealed that there were hyperostosis in the skull base, maxillofacial and frontal bone structures. In addition to extreme hypoplazic appearance in the sphenoid sinus, the other periorbital sinuses were not monitored in CT images due to their abnormal ossification (Fig. 4a, b). In her visual field examination using the Humphrey field analyser, we noted remarkable enlarged blind spot and bitemporal partial hemianopia (Fig. 5a). As the papilledema regressed spontaneously and neurological examination of the patient was normal, we decided to follow up our patient with OCT and visual field tests without treatment. In her last control examination, bilateral best corrected visual acuity was $6 / 10$. Anterior segment examinations were normal. Bilateral colour vision examinations using Ishihara plates were normal. Bilateral optic discs were pallor (Fig. 2b). RNFL analyses of both her eyes still revealed distinct thinning (Fig. 2b). In her visual field examination, despite the improvement in the enlarged blind spot, bitemporal partial hemianopia was still remarkable (Fig. 5b).

\section{Discussion}

Osteogenesis imperfecta is a polygenic disease with a variable phenotype spanning mild to lethal. The majority of mutations associated with OI occur in Type 1 collagen encoding genes (COL1A1, COL1A2) and give rise to an autosomal dominant form of the disease. Novel mutations in seven other genes involved in collagen assembly and processing and in two genes involved in cellular differentiation have recently been associated with autosomal recessive forms of OI [1].

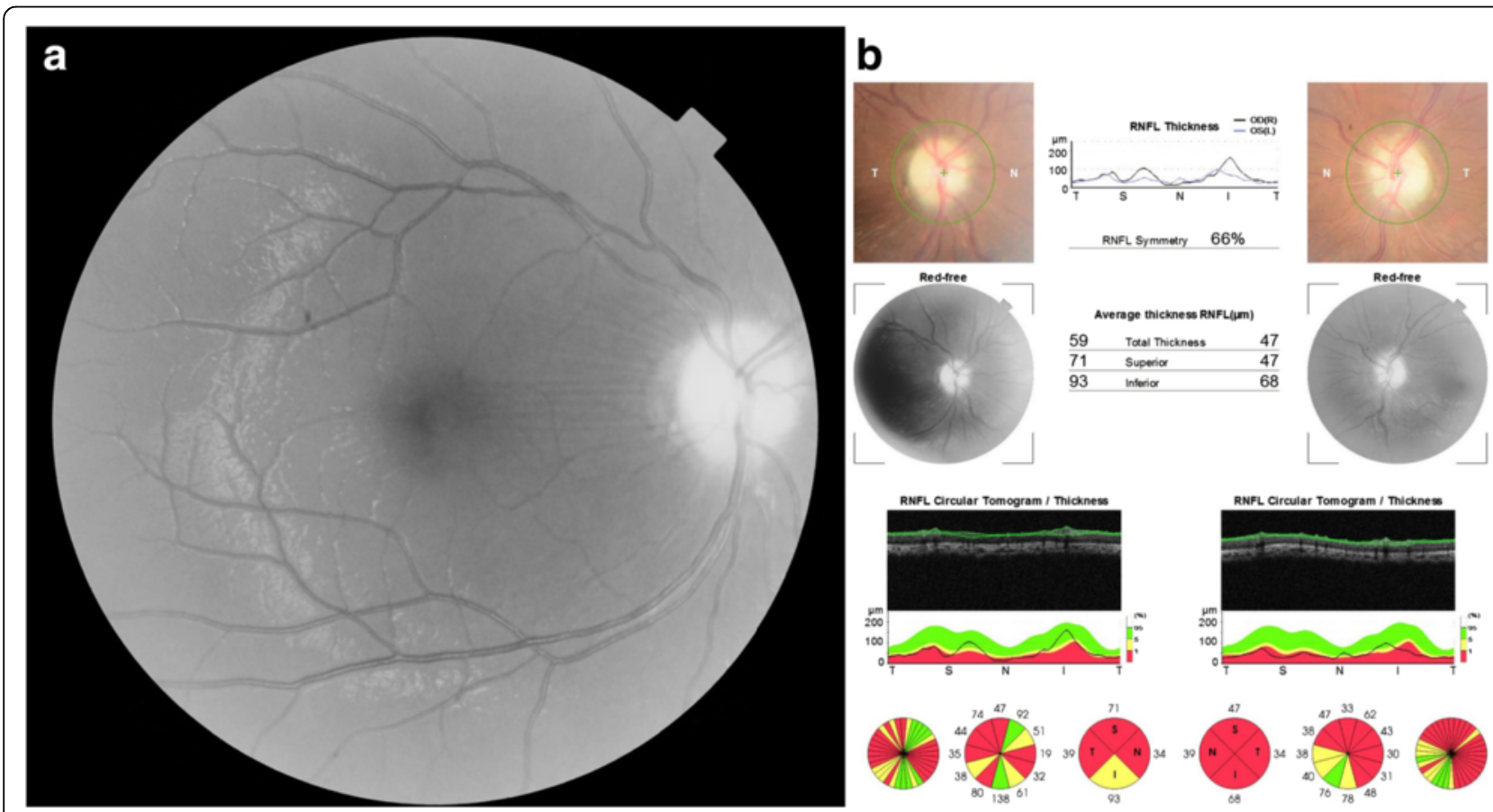

Fig. 2 a The picture shows stage 2 papilledema and wrinkles in the papillomacular area during her fundus examination. $\mathbf{b}$ In her fundus examination after 5 months, the picture shows the bilateral optic discs pallidness and the distinct thinnings in her both retinal nerve fibre layers 

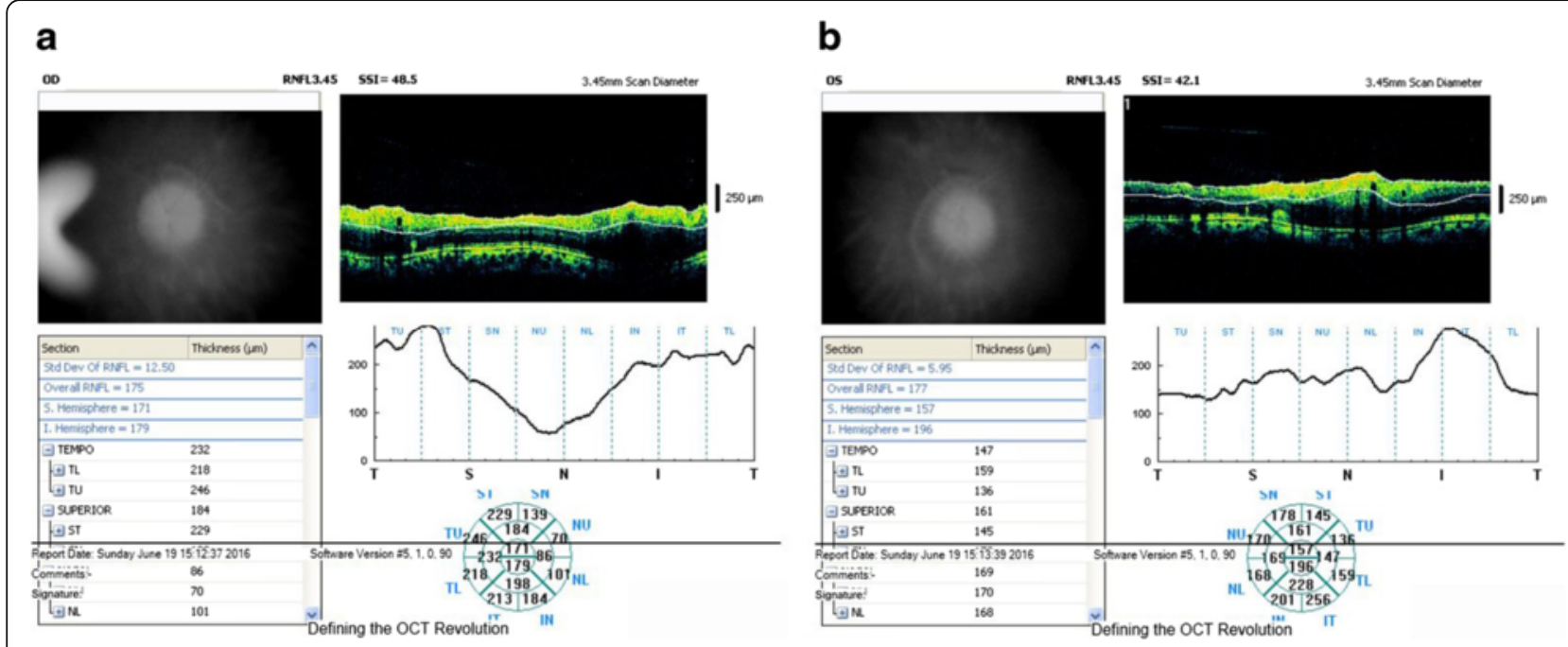

Fig. 3 In her initial retinal nerve layer analysis, there seemed to be a thickening of both retinal nerve fibre layers due to bilateral papilledema. (a Right, $\mathbf{b}$ Left)

In 1979, Sillence and Danks used clinical, radiographic and genetic characteristics to distinguish four groups of patients with OI [13]. Type 1 typically has the mildest musculoskeletal phenotype with common fractures but rare bony deformities and possess the clearest blue scleral hue. Type 2 is the most severe form of OI and is typically lethal during the perinatal period. Individuals with type 3 OI have progressive bone deformations and short stature with blue sclera that fades with age. In those with type $4 \mathrm{OI}$, bone involvement is variable, dental abnormalities are common, and the sclera is normal or greyish in colour. While our patient's findings were most consistent with type 4 , genetic confirmation of the diagnosis was unavailable.

The measures of incidence and prevalence vary among studies but composite evidence suggest that the incidence is probably just over 1 out of 10,000 births and prevalence is a little less, which takes into account the perinatal deaths of those with lethal forms of OI. OI has been reported throughout the world with no selection of race or gender. It could be estimated that $0.008 \%$ of the world's population has OI. In other words, 500,000 persons worldwide would have been afflicted with OI [12].

Patients with OI could have some eye disorders. The present findings of our patient in her initial consultation were low vision, refractive errors (hyperopia), papilledema, macular wrinkle in the papillomacular bundle. We thought that the causes of low vision in our patient were due to both macular wrinkles and amblyopia because of the absence of wearing glasses at a younger age. On the other hand, the interesting point of this case for us was bitemporal partial hemianopia, which emerged together with papilledema and then persisted. Especially in case of bilateral papilledema, the reasons that cause an increase in intracranial pressure should be ruled out. As the neurological examination and intracranial pressure of our patient were normal, we thought that bilateral papilledema and visual field defects were most

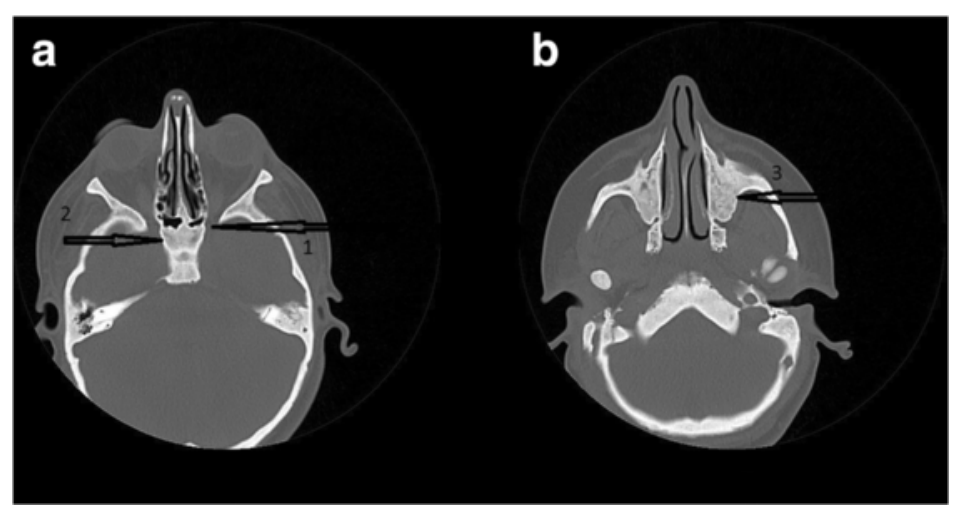

Fig. 4 These axial tomography photographs show an ossification in the optic chiasma (a) and occlusion in all periorbital sinus areas (b) 
a

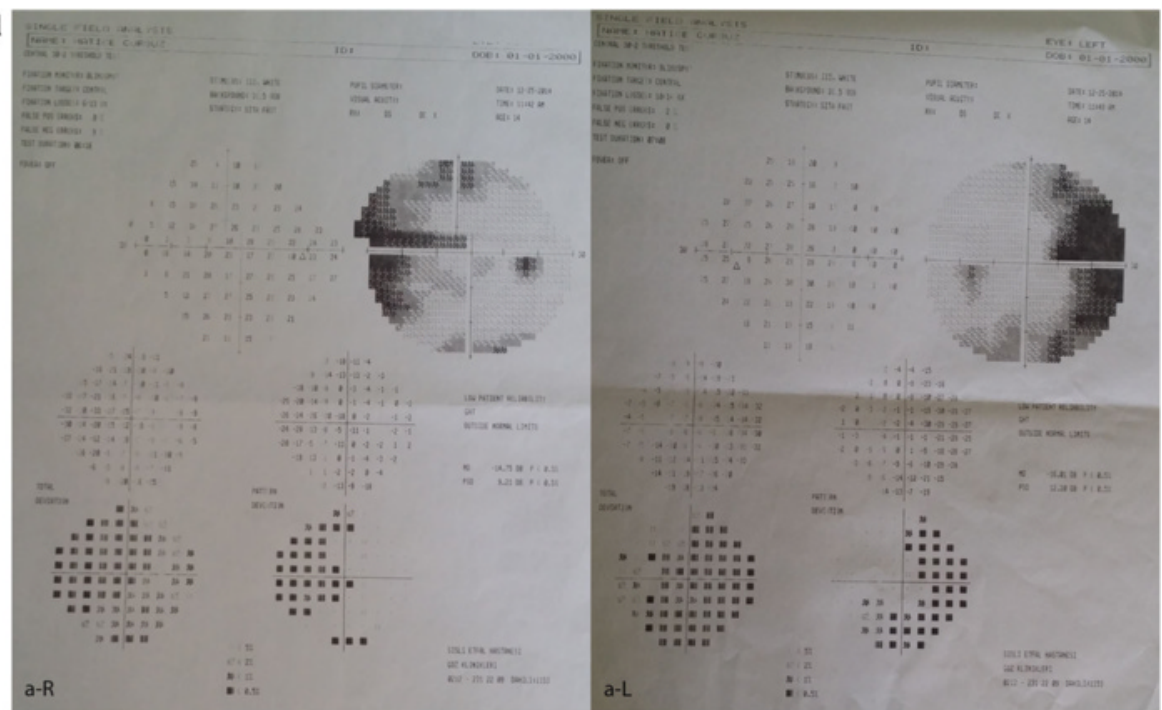

b

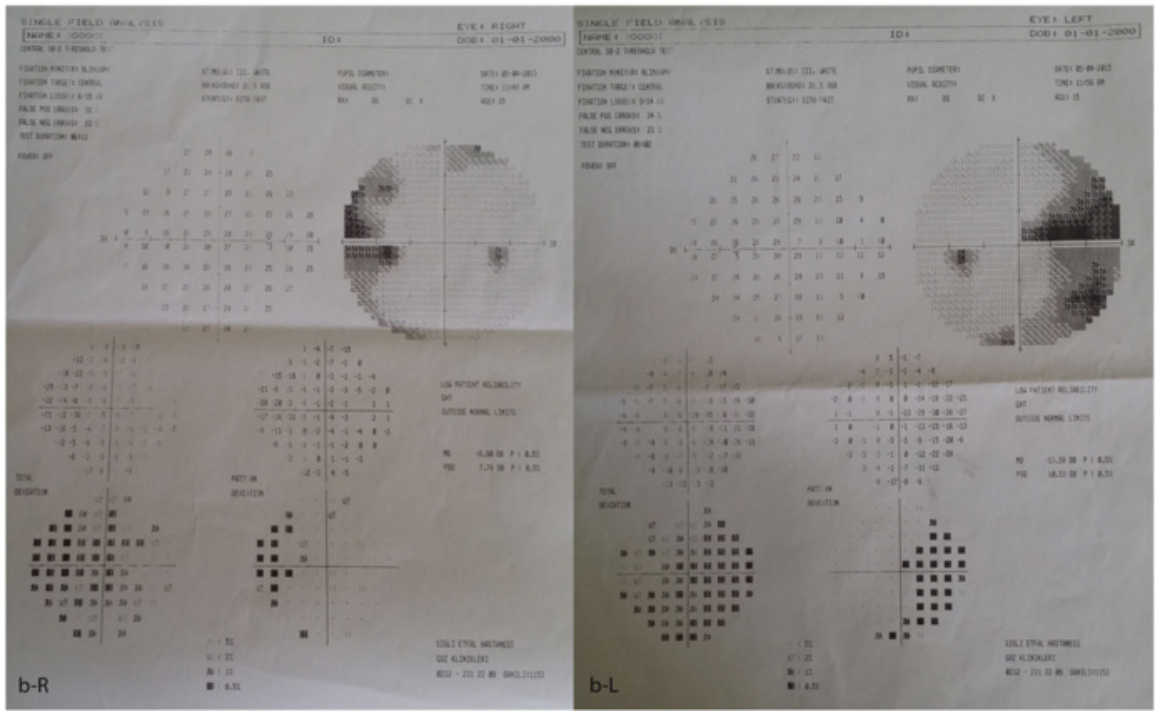

Fig. 5 a, b Bitemporal partial hemianopia is seen in her Humphrey visual field examination. Enlarged blind spot in the papilledema period is remarkable. a Bitemporal partial hemianopia and enlarged blind spots in papilledema period of right and left eyes. (R: Right, L: Left). b After 5 months, while enlarged blind spots were improved along with decrease in papilledema, bitemporal partial hemianopia became more obvious. (R: Right, L: Left)

probably due to abnormal ossifications and microfractures in the optic channel and optic chiasma. While the abnormal ossification that cause the local pressure to optic nerve head may result in papilledema, the compression to optic chiasma may result in visual field defects.

Papilledema related to OI is a rare complication. In addition to our case, there is a case report with optic atrophy in the literature from Russia [14].

\section{Conclusions}

As the eye conditions are common in the OI population, these patients should have eye examinations annually, or at any time new visual symptoms may arise. As with our patient, serious symptoms such as papilledema can even be detected in a routine eye examination.

\section{Acknowledgments}

We thank Yavuz Celik for editing the paper in terms of English.

\section{Authors' contributions}

SYS and ST conceived the idea for the case study and followed the patient. CUA wrote the article and DG revised it critically for important intellectual content. All authors read and approved the final manuscript.

\section{Competing interests}

The authors declare that they have no competing interests.

\section{Consent for publication}

Written informed consents were obtained from both the parents and patient for publication of this Case Report and any accompanying images. A copy of the written consent is available for review by the editor of this journal. 


\section{Author details}

'Department of Ophthalmology, Sisli Hamidiye Etfal Training and Research Hospital, Etfal Street, 34280 Istanbul, Sisli, Turkey. ${ }^{2}$ Department of Ophthalmology, Ulucanlar Eye Training and Research Hospital, Ulucanlar street, 06030 Ankara, Altindag, Turkey.

Received: 12 April 2016 Accepted: 26 September 2016

Published online: 17 October 2016

\section{References}

1. Cundy T. Recent advances in osteogenesis imperfecta. Calcif Tissue Int. 2012;90(6):439-49.

2. Sillence $D$, Butler $B$, Latham $M$, Barlow K. Natural history of blue sclerae in osteogenesis imperfecta. Am J Med Genet. 1993;45:183-6.

3. Kaiser-Kupfer MI, Podgor MJ, McCain L, Kupfer C, Shapiro JR. Correlation of ocular rigidity and blue sclerae in osteogenesis imperfecta. Trans Ophthalmol Soc U K. 1985;104:191-5.

4. Chan CC, Green WR, de la Cruz ZC, Hillis A. Ocular findings in osteogenesis imperfecta congenita. Arch Ophthalmol. 1982;100:1458-63.

5. Khalil MK. Subhyaloid haemorrhage in osteogenesis imperfecta tarda. Can J Ophthalmol. 1983;18:251-2.

6. Beighton P, Winship I, Behari D. The ocular form of osteogenesis imperfecta: a new autosomal recessive syndrome. Clin Genet. 1985;28:69-75.

7. Superti-Furga A, Pistone F, Romano C, Steinmann B. Clinical variability of osteogenesis imperfecta linked to COL1A2 and associated with a structural defect in the type I collagen molecule. J Med Genet. 1986;26:358-62.

8. Kasner L, Mietz H, Green WR. Agenesis of Bowman's layer. A histopathological study of four cases. Cornea. 1993;12:163-70.

9. al Gazali LI, Sabrinathan K, Nair KG. A syndrome of osteogenesis imperfecta, optic atrophy, retinopathy and severe developmental delay in two sibs of consanguineous parents. Clin Dysmorphol. 1994;3:55-62.

10. Madigan WP, Wertz D, Cockerham GC, Thach AB. Retinal detachment in osteogenesis imperfecta. J Pediatr Ophthalmol Strabismus. 1994;31:268-9.

11. Beckh U, Schönherr U, Naumann GO. Autosomal dominant keratoconus as the chief ocular symptom in Lobstein osteogenesis imperfecta tarda. Klin Monatsbl Augenheilkd. 1995;206:268-72.

12. Evereklioglu C, Madenci E, Bayazit YA, Yilmaz K, Balat A, Bekir NA. Central corneal thickness is lower in osteogenesis imperfecta and negatively correlates with presence of blue sklera. Ophthalmic Physiol Opt. 2002:22:511-5

13. Sillence DO, Senn A, Danks DM. Genetic heterogeneity in osteogenesis imperfecta. J Med Genet. 1979;16:101-16.

14. Kadasheva AB, Cherekaev VA, Arutiunov NV, Galkin MV. Rare observation of hyperostotic cranial lesions in osteogenesis imperfecta. Zh Vopr Neirokhir Im N N Burdenko. 2010;2:24-8.

\section{Submit your next manuscript to BioMed Central and we will help you at every step:}

- We accept pre-submission inquiries

- Our selector tool helps you to find the most relevant journal

- We provide round the clock customer support

- Convenient online submission

- Thorough peer review

- Inclusion in PubMed and all major indexing services

- Maximum visibility for your research

Submit your manuscript at www.biomedcentral.com/submit 